Check for updates

Cite this: Mater. Adv., 2021, 2, 2739

Received 11th January 2021 Accepted 7th March 2021

DOI: 10.1039/d1ma00023c

rsc.li/materials-advances

\title{
Rapid fabrication of MOF-based mixed matrix membranes through digital light processing $\dagger$
}

\author{
Alexey Pustovarenko, (D) a Beatriz Seoane, ${ }^{b}$ Edy Abou-Hamad, (D) ${ }^{c}$ Helen E. King, ${ }^{d}$ \\ Bert M. Weckhuysen, (D) ${ }^{b}$ Freek Kapteijn (D) ${ }^{\text {e }}$ and Jorge Gascon (D) *a
}

\begin{abstract}
3D printing, also known as additive manufacturing technology, has greatly expanded across multiple sectors of technology replacing classical manufacturing methods by combining processing speed and high precision. The scientific interest in this technology lies in the ability to create solid architectures with customized shapes and predetermined properties through the exploration of formulations enriched with multifunctional microporous additives such as metal-organic frameworks (MOFs). The concept of additive manufacturing involving advanced materials could be fruitfully adapted for MOF-based mixed matrix membrane fabrication to be used in gas separation applications. In this work, a digital light processing (DLP) approach for fast prototyping of MOF-based mixed matrix membranes (MOF-MMMs) with full control over the shape, size and thickness of the resulting composite using a conventionally available 3D printer has been explored. MOF-based printable inks have been formulated from a selection of commercially available acrylate oligomers and $\mathrm{MIL}-53(\mathrm{Al})-\mathrm{NH}_{2}$ additive post-synthetically modified with methacrylic functionality. The formulations and resulting composites have been extensively characterized to demonstrate the suitability of the inks for DLP processing into free-standing MOF-based membranes. The MOF filler anchored to the polymeric matrix enhances the overall permeability at constant selectivity when applied for $\mathrm{H}_{2} / \mathrm{CO}_{2}$ separation. The obtained results confirm the applicability of the 3D DLP technology for fast prototyping of MOF-based MMMs and provide new opportunities for further development.
\end{abstract}

\section{Introduction}

3D printing technology is a rapidly developing field. ${ }^{1-4}$ Nowadays, fast prototyping is slowly displacing classical manufacturing methods for advanced materials, offering relative operational simplicity and the ability to render a customized

\footnotetext{
${ }^{a}$ King Abdullah University of Science and Technology, KAUST Catalysis Center, Advanced Catalytic Materials, Thuwal 23955, Saudi Arabia. E-mail: jorge.gascon@kaust.edu.sa

${ }^{b}$ Utrecht University, Debye Institute for Nanomaterials Science, Inorganic Chemistry and Catalysis Group, Universiteitsweg 99, 3584 CG Utrecht, The Netherlands ${ }^{c}$ King Abdullah University of Science and Technology, Core Labs, Thuwal 23955, Saudi Arabia

${ }^{d}$ Department of Earth Sciences, Utrecht University, Princetonlaan 8a, 3584 CB, Utrecht, The Netherlands

${ }^{e}$ Delft University of Technology, Department of Chemical Engineering, Van der Maasweg 9, $2629 \mathrm{HZ}$ Delft, The Netherlands

$\dagger$ Electronic supplementary information (ESI) available: Chemical schemes of commercial oligomers; tables with ink formulation composition; DLP 3D printed details and specifications; additional figures; $\mathrm{N}_{2}$ and Ar adsorption data and plots; TEM images and particle size distribution histograms; NMR data and plots; FTIR; viscosity data; ATR-IR, kinetic data of photopolymerization in systems with and without MOF additive; Raman spectra and mapping; mechanical data; optic microscope images; SEM-EDX maps; data on degree of crosslinking; TG and DSC analyses; gas separation performance data. See DOI: 10.1039/d1ma00023c
}

product at high speeds and with high precision. ${ }^{5}$ Bridging the gap between fast prototyping and functionality, additive manufacturing is a very interesting playground for the development of formulations that can enable the fabrication of complex forms of matter with specific properties on demand. , $^{6}$

To amplify and broaden the applicability prospects of additive compositions, the incorporation of multifunctional components such as microporous solids can be considered to endow the additive formulations with additional properties. ${ }^{8,9}$ From this perspective, metal-organic frameworks (MOFs) are promising filler candidates. ${ }^{10-15}$

Conceptually, the integration of a MOF component into additive formulations has been approached and then realized through different 3D printing techniques ${ }^{4}$ - inkjet, ${ }^{16,17}$ direct ink writing (DIW), ${ }^{18-27}$ fused deposition modelling (FDM), ${ }^{28-30}$ digital light processing (DLP) ${ }^{31}$ and selective laser sintering (SLS). ${ }^{32,33}$ For instance, photoluminescent lanthanide MOFbased inks for inkjet printing were reported by da Luz et al. ${ }^{16}$ In addition to examples of MOF coatings grown on 3D printed objects obtained by stereolithography (SLA) ${ }^{34}$ or direct ink writing, ${ }^{24}$ fabrication of monoliths with full integration of the MOF component within a melting matrix of acrylonitrile butadiene styrene (ABS), ${ }^{28,29}$ poly(lactic acid) (PLA) or thermoplastic 
polyurethane (TPU) ${ }^{30}$ has been achieved using fused deposition modelling. However, the FDM processable MOF/thermoplastic composites frequently suffer from a porosity loss that questions their further applicability. ${ }^{28}$ Unlike in the FDM approach, firm monoliths with accessible internal porosity, suitable for applications involving adsorption, have been obtained via direct ink writing. Moreover, several representative examples of composites with high MOF loading ${ }^{22}$ suitable for gas separation, ${ }^{18,20,21}$ catalysis, ${ }^{26}$ molecule sequestration and release have been reported. ${ }^{19,25}$ Similarly, tailored shapes with high MOF content $\mathrm{t}^{32}$ can be fabricated by means of selective laser sintering (SLS) into self-standing MOF-polymer mixed matrix films. ${ }^{33}$

From the perspective of using 3D printable MOF-containing additives for gas separation and, particularly, for fast prototyping of MOF-based mixed matrix membranes (MOF-MMMs), ${ }^{35}$ the digital light processing (DLP) technique deserves particular attention. DLP printing proceeds through the solidification of liquid resins by photoinduced crosslinking on locally illuminated areas, reproducing in this way a 3D shape in a stepwise manner (layer by layer). Thus, the process not only affords fast prototyping but also endows a control over resolution - thickness of the layer, which is an important aspect to consider while dealing with mixed matrix membranes. Building on the work of Halevi et $a .^{31}$ on DLP processing of a MOF/acrylate admixture into 3D printed shapes and an early study of Zhang et al. ${ }^{36}$ on copolymerization between post-synthetically functionalized with methyl methacrylate UiO-66- $\mathrm{NH}_{2}$ particles and an acrylate monomer, we are targeting to adapt the previous contributions for fast prototyping of MOF-based mixed matrix membranes (MOF-MMMs).

Herein, we explore a digital light processing technology for fast prototyping of MOF-MMMs. With this approach, MIL-53(Al)- $\mathrm{NH}_{2}$ nanoparticles post-synthetically functionalized with a methacrylic moiety could be covalently integrated within a photopolymerizable matrix of commercially available acrylic oligomers for the further fabrication of MOF-MMMs with a controllable thickness and tailored shape in a matter of minutes without the need for additional solvents or long post-synthetic treatment. Given the fact that the DLP 3D printing technique involving MOF-based inks is currently poorly represented while the approach offers a range of attractive benefits such as rapidness of prototyping with no molds and solvents engaged, herein, we critically evaluate aspects relevant for DLP processing of several acrylate systems with and without MOF-additives into membranes aimed to be applied for the separation of an equimolar $\mathrm{H}_{2} / \mathrm{CO}_{2}$ mixture.

\section{Experimental section}

\subsection{Materials and synthetic procedures}

Materials. Aluminum nitrate nonahydrate $\left(\mathrm{Al}\left(\mathrm{NO}_{3}\right)_{3} \cdot 9 \mathrm{H}_{2} \mathrm{O}\right.$, 99.997\% trace metals basis), sodium hydroxide ( $\mathrm{NaOH}$, pellets), 2aminoterephthalic acid (2-ATA, 99\%), N,N-dimethylformamide (DMF, >99.8\%), methacrylic anhydride (MMA, 94\%), phenylbis(2,4,6-trimethylbenzoyl)phosphine oxide (Irgacure ${ }^{\circledR}-819,97 \%$ ), tetrahydrofuran (THF), and chloroform ( $\mathrm{CHCl} 3)$ were purchased from Sigma-Aldrich. Methanol was supplied by VWR Chemicals
( $\geq 99.8 \%$ ACS). Ethoxylated-4-bisphenol-A-dimethacrylate (SR540), aliphatic urethane dimethacrylate (CN1963), trimethylolpropane trimethacrylate (SR350D) and amine-modified polyether acrylate (CN501) were kindly provided by Sartomer (Arkema Group).

Synthesis of MIL-53(Al)- $\mathrm{NH}_{2}$ nanoparticles. Nanoparticles of MIL-53(Al)- $\mathrm{NH}_{2}$ were synthesized following a previously reported protocol, ${ }^{37}$ where $1.90 \mathrm{~g}$ of 2-aminoterephthalic acid (10.50 mmol) was dissolved in $10.5 \mathrm{~mL}$ of aqueous $2 \mathrm{M} \mathrm{NaOH}$ solution at room temperature. Afterwards, $6.11 \mathrm{~g}$ of $\mathrm{Al}\left(\mathrm{NO}_{3}\right)_{3} \cdot 9 \mathrm{H}_{2} \mathrm{O}(16.30 \mathrm{mmol})$ dissolved in $64.5 \mathrm{~mL}$ of deionized water was added to the previous solution and the resulting mixture was magnetically stirred for $15 \mathrm{~min}$. Then, the reactant mixture was refluxed for 3 days without stirring, resulting in a yellow product that was filtered under vacuum. The product yield was $1.2 \mathrm{~g}$.

Post-synthetic modification of MIL-53(Al)- $\mathrm{NH}_{2}$ with methacrylate functionality. Post-synthetic modification of MIL-53(Al)$\mathrm{NH}_{2}$ nanoparticles with photocrosslinkable functional groups was achieved through acylation of $-\mathrm{NH}_{2}$ with methacrylic anhydride following a procedure adapted from previous works. ${ }^{36,38}$ In a typical experiment, $300 \mathrm{mg}$ of dry MIL-53(Al)$\mathrm{NH}_{2}$ powder was transferred into a two-neck flask equipped with a condenser and a magnetic stirring bar and filled with nitrogen gas using a Schlenk line. Then, the powder was suspended in $20.0 \mathrm{~mL}$ of $\mathrm{CHCl}_{3}$, and $1.0 \mathrm{~mL}$ of methyl methacrylic (MMA) anhydride was added to the stirring mixture in a nitrogen atmosphere. The temperature of the reaction mixture was raised to $80{ }^{\circ} \mathrm{C}$ and left to react for $10 \mathrm{~h}$. Afterwards, the suspension was cooled and the resulting solid MIL-53(Al)- $\mathrm{NH}_{2} / \mathrm{MMA}$ was washed several times with $\mathrm{CHCl}_{3}$. The suspension was then dried under reduced pressure at $80{ }^{\circ} \mathrm{C}$ for $5 \mathrm{~h}$ after which it was activated by washing with $N, N$-dimethylformamide at $130{ }^{\circ} \mathrm{C}$, and subsequently with methanol under reflux, both overnight. Finally, the powder was thoroughly washed twice with ethanol, dried at $100{ }^{\circ} \mathrm{C}$ under vacuum, yielding $285 \mathrm{mg}$ of the product which was stored in a glovebox for further experiments.

\subsection{Ink formulations and 3D printing process}

Photopolymerizable ink formulation for the DLP process. DLP printable inks were prepared by admixing a certain mass of individual photopolymerizable oligomers (Fig. S1, ESI $\dagger$ ), i.e. ethoxylated-4-bisphenol-A-dimethacrylate (E-component, SR540), aliphatic urethane dimethacrylate (U-component, CN1963), trimethylolpropane trimethacrylate (T-component, SR350D), and amine-modified polyether acrylate (P-component, CN501), and their mixtures with a photoinitiator Irgacure ${ }^{\mathbb{R}}-819$ (Fig. S2, ESI $\dagger$ ). For MOF-based ink variations, MIL-53(Al)- $-\mathrm{NH}_{2} / \mathrm{MMA} \mathrm{PSM}$ nanoparticles were admixed with commercial acrylate-based components (E-, U-, T-, P-oligomers) or a mixture of the components along with the Irgacure ${ }^{\mathbb{R}}-819$ photoinitiator in a mass proportion according to Table S1 (ESI $\dagger$ ). Typically, photopolymerizable MOF-based formulations containing $12 \mathrm{wt} \%$ of MIL-53(Al)-NH $/$ MMA were prepared by mixing the components and stirring for 20-30 min to reach stable suspensions. Afterwards, the heterogeneous mixture was poured into the resin vat of a $3 \mathrm{D}$ printer. 
3D printing of polyacrylate membranes. All printed materials were prepared using a Kudo3D model Titan 2 printer operating in a digital light processing (DLP) mode (Table S2 and Fig. S3, S4, ESI $\dagger$ ) with parameter settings detailed in Table S3 (ESI $\dagger$ ). Spectral irradiance of the 3D printer light source was measured with an AvaSpec-3648-2-USB2 probe from Avantes (Fig. S5 and Table S4, ESI $\dagger$ ). The printed membranes were detached from the build platform, washed with isopropanol to remove the remaining unpolymerized ink and dried at $80{ }^{\circ} \mathrm{C}$ for $1 \mathrm{~h}$ in a conventional oven.

Determination of crosslinking degree and methacrylic group conversion. The degree of crosslinking was determined following the Soxhlet extraction method detailed in ASTM with some adaptations. ${ }^{39}$ According to this method, several specimens were cut from different segments of each photopolymerized membrane and weighed to determine the initial mass $\left(m_{i}\right)$, then the specimen was divided into smaller $0.5 \mathrm{~cm} \times 0.5 \mathrm{~cm}$ pieces and soaked in tetrahydrofuran (THF) at room temperature for $24 \mathrm{~h}$. As the photopolymerizable precursors are soluble in THF, a noncrosslinked fraction of oligomers is expected to be removed from the composite leaving the crosslinked polymer matrix. Consequently, the remaining solid fraction was dried up at $80{ }^{\circ} \mathrm{C}$ for $24 \mathrm{~h}$ and weighed to determine its residual weight $\left(m_{\mathrm{f}}\right)$. The degree of crosslinking (DC) was calculated as follows (eqn (1)):

$$
\mathrm{DC}(\%)=\frac{m_{\mathrm{f}}}{m_{i}} \times 100 \%
$$

Methacrylic group conversion was followed by attenuated total reflection-Fourier transform infrared (ATR-FTIR) real-time measurements to evaluate the kinetics of cross-linking and to quantitatively express the degree of conversion in each studied ink formulation. The degree of methacrylic group conversion $\left(X_{\mathrm{MMA}}\right)$ was derived from the intensity of the methacrylate group absorption centered at $\sim 1640 \mathrm{~cm}^{-1}$ and calculated according to eqn (2):

$$
X_{\mathrm{MMA}}(\%)=\left(1-\frac{A_{t}}{A_{i}}\right) \times 100 \%
$$

where $A_{t}$ and $A_{i}$ are the areas of the methacrylate group absorption in the beginning and at the moment $t$ of exposure to the light, respectively.

\subsection{General characterization}

Scanning powder X-ray diffraction (PXRD) patterns were recorded using a Bruker D8 Advance operated with monochromatic $\mathrm{Cu}-\mathrm{K} \alpha$ $(\lambda=1.5418 \AA)$ radiation with a scan speed of $0.5 \mathrm{~s}$ per step and a step size of $0.1^{\circ}$ over the $5-60^{\circ} 2 \theta$ range.

Physisorption isotherms using nitrogen and argon gas probes were recorded at $77 \mathrm{~K}$ and at $87 \mathrm{~K}$, respectively, using a Micromeritics ASAP 2040 instrument. Carbon dioxide physisorption isotherms were recorded using a Tristar II 3020 at $273 \mathrm{~K}$. Before the measurement, composite samples were degassed at $150{ }^{\circ} \mathrm{C}$ for $8 \mathrm{~h}$. The uptake measurements for MIL-53(Al)- $\mathrm{NH}_{2}$ and MIL-53(Al)- $\mathrm{NH}_{2} / \mathrm{MMA}$ were conducted on an activated sample treated according to the well-known procedure described elsewhere. ${ }^{37,40,41}$

Thermogravimetric data (TG) were collected in nitrogen and air atmospheres using a Mettler-Toledo thermal analyzer at a heating rate of $5{ }^{\circ} \mathrm{C} \min ^{-1}$ in a $25-800{ }^{\circ} \mathrm{C}$ temperature range with a gas flow of $25 \mathrm{~mL} \mathrm{~min}^{-1}$.

Differential scanning calorimetry (DSC) tests were carried out using a Mettler-Toledo TGA/DSC1 Star system by heating

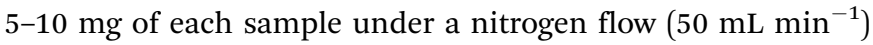
from 40 up to $230{ }^{\circ} \mathrm{C}$ applying a heating rate of $10{ }^{\circ} \mathrm{C} \mathrm{min}{ }^{-1}$ and cooling rate of $5{ }^{\circ} \mathrm{C} \mathrm{min}^{-1}$. Three consecutive runs were performed. The first cycle was intended to remove any previous thermal history of the samples. Two subsequent cycles were performed using the same protocol.

Transmission electron microscopic (TEM) images were obtained using a JEOL JEM-2100F microscope operated at $120 \mathrm{kV}$ and equipped with a field emission gun (FEG). The samples were dispersed in methanol, sonicated and sprayed on a carboncoated copper grid and air-dried.

Scanning electron microscopic (SEM) imaging was performed using an FEI TENEO VS microscope equipped with an integrated SDD EDX detector. 3D printed samples were mounted on a $45^{\circ} / 90^{\circ}$ holder with the help of double-sided carbon tape and grounded with strokes of conductive silver paint. For cross-sectional evaluation, printed films were cryo-fractured in liquid nitrogen. FIB-SEM cross-sectional studies were carried out using a Helios Nanolab 600 FIB.

Solid-state nuclear magnetic resonance (ssNMR) spectroscopy. One-dimensional ${ }^{1} \mathrm{H}$ MAS and ${ }^{13} \mathrm{C}$ CP/MAS solid-state NMR spectra were recorded using Bruker AVANCE III spectrometers operated at 400 or $600 \mathrm{MHz}$ resonance frequency for ${ }^{1} \mathrm{H}$. A conventional double-resonance $4 \mathrm{~mm} \mathrm{CP} / \mathrm{MAS}$ probe was used for experiments at $400 \mathrm{MHz}$, while a $3.2 \mathrm{~mm}$ double-resonance probe was used for experiments at $600 \mathrm{MHz}$. NMR chemical shifts are reported with respect to the external references TMS and adamantane. For ${ }^{13} \mathrm{C} \mathrm{CP} / \mathrm{MAS}$ NMR experiments, the following sequence was used: $90^{\circ}$ pulse on the proton (pulse length $2.4 \mathrm{~s}$ ), then a cross-polarization step with a contact time of typically $2 \mathrm{~ms}$, and finally, the acquisition of the ${ }^{13} \mathrm{C}$ signal under high-power proton decoupling. The delay between the scans was set to $5 \mathrm{~s}$ to allow the complete relaxation of the ${ }^{1} \mathrm{H}$ nuclei, and the number of scans ranged between 10000 and 20000 for ${ }^{13} \mathrm{C}$ and was 32 for ${ }^{1} \mathrm{H}$. An exponential apodization function corresponding to a line broadening of $80 \mathrm{~Hz}$ was applied prior to Fourier transformation.

The 2D ${ }^{1} \mathrm{H}_{-}{ }^{13} \mathrm{C}$ heteronuclear correlation (HETCOR) solidstate NMR spectroscopic experiments were conducted using a Bruker AVANCE III spectrometer with a $3.2 \mathrm{~mm}$ MAS probe. The experiments were performed according to the following scheme: $90^{\circ}$ proton pulse, $t_{1}$ evolution period, CP to ${ }^{13} \mathrm{C}$, and detection of the ${ }^{13} \mathrm{C}$ magnetization under TPPM decoupling. For the cross-polarization step, a ramped radio frequency (RF) field centered at $75 \mathrm{kHz}$ was applied to the protons, while the ${ }^{13} \mathrm{C}$ channel RF field was matched to obtain an optimal signal. A total of $64 t_{1}$ increments with 2000 scans each were collected. The sample spinning frequency was $15 \mathrm{kHz}$. Using a contact time of $0.2 \mathrm{~ms}$ for the CP step, the polarization transfer in the 
dipolar correlation experiment was verified to be selective for the first coordination sphere $(<5 \AA)$.

Dynamic nuclear polarization (DNP) NMR spectroscopy. TEKPol was dried under high vacuum $\left(10^{-4} \mathrm{mbar}\right)$ and the solvents were stirred over calcium hydride and then distilled in vacuo. A radical solution consisting of $16 \mathrm{mM}$ TEKPol (TEKPol, $\mathrm{MW}=905 \mathrm{~g} \mathrm{~mol}^{-1}$ ) in 1,1,2,2-tetrachloroethane (TCE) was used. The compounds and the corresponding nitrides synthesized were finely ground in a mortar and pestle prior to the preparation of DNP experiments. DNP samples were then prepared by incipient wetness impregnation. In a typical experiment, $15 \mathrm{mg}$ of the samples were impregnated with the appropriate volume of $16 \mathrm{mM}$ solution of TEKPol (nTEKPol $=0.5-1.2 \mu \mathrm{mol}$ per sample) and packed into a $3.2 \mathrm{~mm}$ (o.d.) sapphire rotor capped with a Teflon plug. The packed samples were then immediately inserted into the pre-cooled DNP probe for experiments. Data were acquired using a $263 \mathrm{GHz} / 400 \mathrm{MHz}$ Avance III Bruker DNP solid-state NMR spectrometer equipped with a $3.2 \mathrm{~mm}$ Bruker triple-resonance low-temperature magic angle spinning (LTMAS) probe and the experiments were performed at $c a .100 \mathrm{~K}$ with a $263 \mathrm{GHz}$ gyrotron. The sweep coil of the main magnetic field was set for the microwave irradiation occurring at the ${ }^{1} \mathrm{H}$ positive enhancement maximum of the TEKPol biradical. For the ${ }^{15} \mathrm{~N}$ CP-MAS DNP experiments, the acquisition parameters included a $3 \mathrm{~s}$ repetition delay and a ${ }^{1} \mathrm{H} \pi / 2$ pulse length of $2.3 \mu \mathrm{s}$ to afford $100 \mathrm{kHz}{ }^{1} \mathrm{H}$ decoupling using the SPINAL 64 method. The contact time was typically $4 \mathrm{~ms}$ for the cross-polarization experiments. The MAS frequency varied between 8 and $12 \mathrm{kHz}$. The 2D ${ }^{1} \mathrm{H}-{ }^{15} \mathrm{~N}$ HETCOR spectra were recorded with 2048 scans per $t_{1}$ increment, 96 individual increments, and a contact time of $4 \mathrm{~ms}$. During $t_{1}$, e-DUMBO-1 homonuclear ${ }^{1} \mathrm{H}$ decoupling was applied, and the proton chemical shifts were corrected by applying a scaling factor of 0.57 .

Liquid-state nuclear magnetic resonance experiments were performed using a Bruker Advance-400. In the digestion experiment, $10 \mathrm{mg}$ of MIL-53(Al)- $\mathrm{NH}_{2} / \mathrm{MMA}$ was dissolved in a mixture of DMSO-d6/HF resulting in a clear solution.

Attenuated total reflection-Fourier transform infrared spectroscopic (ATR-FTIR) analyses were performed on a home-built setup that included a Nicolet 8700 FTIR spectrometer equipped with a Harrick Horizon multiple internal reflection accessory, coupled to a cell containing a ZnSe crystal. The photopolymerizable ink formulations were layered on the top of the ZnSe crystal and illuminated using an ACER H5360 LED DLP projector. To observe the spectral changes during the photopolymerization process, realtime ATR spectra were recorded in the range of $2000-1000 \mathrm{~cm}^{-1}$ at $1.93 \mathrm{~s}$ intervals. The spectral resolution was $4 \mathrm{~cm}^{-1}$ and 1 scan per time interval was used to achieve the maximum time resolution.

Raman spectroscopic studies were performed using a WITec alpha 300R Raman microscope operated with a $532 \mathrm{~nm}$ laser (14 mW). 2D maps of the 3D printed object surface were acquired on a $30 \mu \mathrm{m} \times 30 \mu \mathrm{m}$ area advancing with $1 \mu \mathrm{m}$ step size along each of the $x, y$ directions.

The stress-strain data were collected using a Zwick Roell tensile testing machine at room temperature. UV polymerized samples were prepared in molds in the form of $55 \times 5 \times 3 \mathrm{~mm}$ blocks and all tested with the applied $150 \mathrm{mN} \min ^{-1}$ loading rate.

An optic microscope Leica DM750 equipped with HI Plan EPI 5/10/20/50 $\times$ objectives and a rotating diascopic polarizer was used to capture the images of $3 \mathrm{D}$ printed objects in bright and dark fields.

\subsection{Gas permeation measurements}

$3 \mathrm{D}$ printed rounded membranes with an area of $0.2 \mathrm{~cm}^{2}$ were mounted on a flange between Viton ${ }^{\circledR} \mathrm{O}$-rings and placed inside an oven in a home-made permeation setup. The $\mathrm{H}_{2} / \mathrm{CO}_{2}$ separation measurements were performed employing an equimolar $\mathrm{H}_{2}: \mathrm{CO}_{2}$ gas mixture $\left(20 \mathrm{~mL} \mathrm{~min}{ }^{-1} \mathrm{CO}_{2}\right.$ and $20 \mathrm{~mL} \mathrm{~min}{ }^{-1} \mathrm{H}_{2}$ ) feed. Helium $\left(2.0 \mathrm{~mL} \mathrm{~min}^{-1}\right)$ was used as a sweep gas at the permeate side. The absolute pressure of the feed stream was adjusted in a range of 1-2 bar using a back-pressure controller at the retentate side, keeping the permeate side at atmospheric pressure. The temperature in the permeation module was adjusted from room temperature to $100{ }^{\circ} \mathrm{C}$ through a convection oven. An on-line gas chromatograph (Interscience Compact GC) equipped with a packed Carboxen 1010 PLOT $(30 \mathrm{~m} \times 0.32 \mathrm{~mm})$ column and a thermal conductivity detector (TCD) was used to periodically analyze the permeate stream.

The permeability of component $j\left(P_{j}\right)$ was calculated as follows (eqn (3)):

$$
P_{j}=\frac{\phi_{n, j} \cdot \delta}{\Delta p_{j} \cdot A}
$$

where $\varphi_{n, j}$ denotes the molar flow rate of component $j, \delta$ is the thickness of the membrane, $\Delta p_{j}$ is the partial pressure difference of component $j$ across the membrane, and $A$ is the membrane area.

The SI unit for permeability is mol s $\mathrm{s}^{-1} \mathrm{~m}^{-1} \mathrm{~Pa}^{-1}$. However, here, gas permeabilities are reported in the widely used non-SI unit Barrer, where 1 Barrer $=3.35 \times 10^{-16} \mathrm{~mol} \mathrm{~m} \mathrm{~m}^{-2} \mathrm{~Pa}^{-1} \mathrm{~s}^{-1}$.

The separation factor or mixed gas selectivity $(\alpha)$ was calculated as the ratio of the permeability of the faster permeating component $\left(\mathrm{H}_{2}\right)$ to the permeability of the less permeable component $\left(\mathrm{CO}_{2}\right)$ as given below (eqn (4)):

$$
\alpha=\frac{P_{\mathrm{H}_{2}}}{P_{\mathrm{CO}_{2}}}
$$

\section{Results and discussion}

MIL-53(Al)- $\mathrm{NH}_{2}$ framework is a MOF widely used for gas storage and separation purposes and reported to demonstrate remarkable performance when incorporated as a filler into mixed matrix membranes (MMMs). ${ }^{37,41}$ In particular, the presence of $\mathrm{NH}_{2}$ groups endows this framework with diverse functionalization opportunities (Fig. 1A). ${ }^{42}$ Thus, the amino groups were brought into play to introduce a photocrosslinkable functionality to MIL-53(Al)- $\mathrm{NH}_{2}$ particles with the aim to improve their processability and integrability into DLP UV-curable inks.

To meet the requirements for an effective integrability into a polymer matrix, a MIL-53(Al)- $\mathrm{NH}_{2}$ material was synthesized in the form of nanoparticles with dimensions of about 30-100 nm 


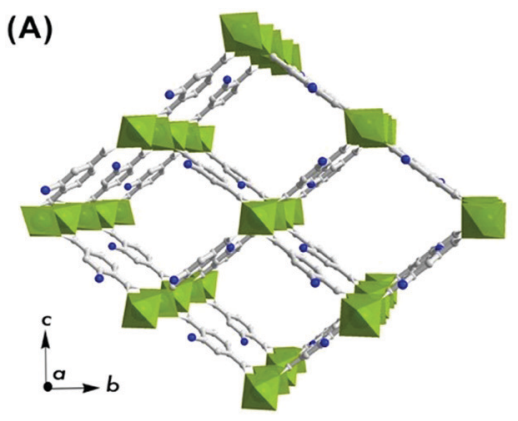

(B)

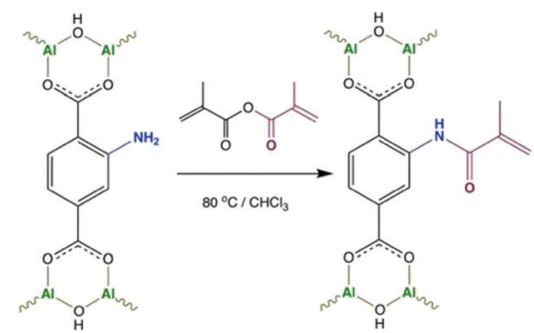

Fig. 1 (A) Representation of MIL-53(Al) $-\mathrm{NH}_{2}$ structure in the open pore configuration, where $\mathrm{AlO}_{6}$ polyhedra are depicted in green, and grey and navy are carbon and nitrogen atoms, respectively. (B) Scheme of postsynthetic modification of MIL-53(Al) $-\mathrm{NH}_{2}$ structure with methyl methacrylic anhydride.

(Fig. S6 and S7, ESI†). The post-synthetic functionalization was made on a non-activated MOF to assure restricted accessibility of the porous system and to favor preferential attachment to $\mathrm{NH}_{2}$-groups on the surface. Hence, the as-synthesized MIL-53(Al)- $\mathrm{NH}_{2}$ was post-synthetically modified (PSM) through an acylation reaction with a methyl methacrylic anhydride (Fig. 1B). Such modification leads to the framework transformation from np- to lp-conformation, ${ }^{43}$ as suggested by Fig. 2A. The latter can be attributed to a partial anchoring of $\mathrm{NH}_{2}$-groups inside the pores of the MOF in addition to the modifications occurring on the surface of the particles. Thus, the incorporation of a bulky MMA group into the pore space forces the framework to adopt the lp-configuration, which is in good agreement with the previous reports on PSM of structures exhibiting "breathing behaviour". ${ }^{40,42}$

In order to confirm the covalent character of the post-synthetic modification of MIL-53(Al)- $\mathrm{NH}_{2}$ with MMA functionality, solidstate nuclear magnetic resonance (NMR) spectroscopic studies were carried out on a pristine MIL-53(Al)- $\mathrm{NH}_{2}$ material and its PSM-NH ${ }_{2} / \mathrm{MMA}$ version. The ${ }^{1} \mathrm{H}$ MAS NMR spectrum (Fig. S8, $\mathrm{ESI}+$ ) of the original MIL-53(Al)- $\mathrm{NH}_{2}$ contains four peaks that can be assigned to the aromatic protons of the linker (unresolved peak at $6.9 \mathrm{ppm})$, protons of the amino group (5.5 ppm) and protons of the bridging $\mu_{2}$-OH group in two possible chemical environments ( $\delta_{\text {iso }}=2.8$ and $1.9 \mathrm{ppm}$ ) as expected. ${ }^{44,45}$ In the $2 \mathrm{D}$ ${ }^{1} \mathrm{H}$ MAS DQ-SQ NMR correlation spectrum (Fig. S9, ESI $\dagger$ ), the aromatic proton resonances remain unresolved albeit manifesting two main pairs of correlation peaks: ${ }^{1} \mathrm{H}^{-1} \mathrm{H}$ correlations between the (i) aromatic protons and $\mathrm{NH}_{2}$-group ( $\delta_{\text {iso }}$ in $\mathrm{F} 2$ dimension: 5.5-6.8 ppm) and between the (ii) aromatic protons and bridging
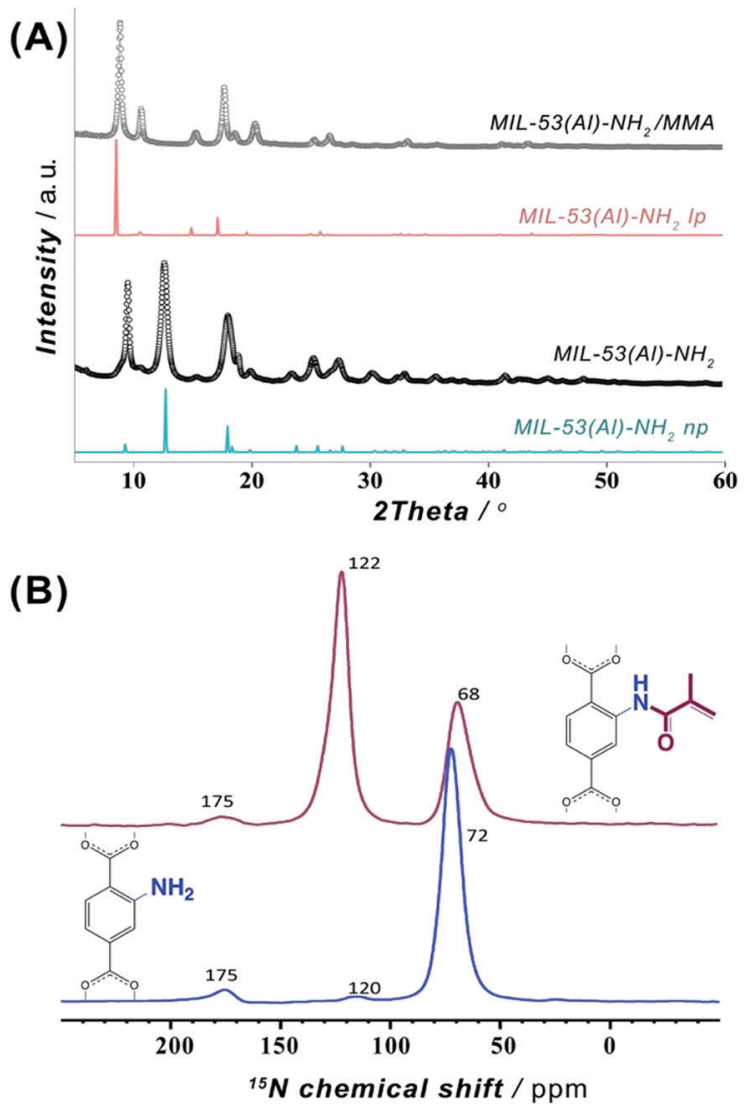

Fig. 2 (A) Powder XRD patterns of MIL-53(Al)- $\mathrm{NH}_{2}$ nanoparticles before (black) and after (grey) post-synthetic modification with MMA and compared to open (lp) and narrow pore (np) forms. (B) Solid-state DNP-enhanced ${ }^{15} \mathrm{~N}$ NMR spectrum for MIL-53(Al)- $\mathrm{NH}_{2}$ before (blue) and after (wine) postsynthetic modification with MMA.

OH group ( $\delta_{\text {iso }}$ in F2 dimension: 1.9-6.8 ppm). The ${ }^{13} \mathrm{C}$ CPMAS NMR spectrum shows six resonances (Fig. S10, ESI $\dagger$ ) attributed to the carbonyl groups in the $\mathrm{NH}_{2}-\mathrm{BDC}$ linker $\left(\delta_{\text {iso }}=175.6 \mathrm{ppm}\right)$ and carbons of the aromatic ring $\left(\delta_{\text {iso }}\right.$ in $116.4-150.5 \mathrm{ppm}$ range). In addition, the intra-linker coupling interactions between the carbon atoms and aromatic protons were complemented by means of a $2 \mathrm{D}^{1} \mathrm{H}^{-13} \mathrm{C}$ HETCOR NMR (Fig. S11, ESI $\dagger$ ). The ${ }^{1} \mathrm{H}$ MAS NMR spectrum (Fig. S12, ESI $\dagger$ ) of the PSM MIL-53(Al)-NH $/$ MMA material reveals additional weakly resolved resonances of $\mathrm{CH}_{3}$-protons $\left(\delta_{\text {iso }} \sim 0.7 \mathrm{ppm}\right), \mathrm{CH}_{2}$ protons $\left(\delta_{\text {iso }} \sim 5.2 \mathrm{ppm}\right)$ of the MMA moiety and amide $-\mathrm{NH}-$ protons $\left(\delta_{\text {iso }} \sim 10.7 \mathrm{ppm}\right)$ that affirm the presence of acylated $\mathrm{NH}_{2}$-groups. Expected changes of the aromatic proton-related chemical shifts upon PSM are also reflected in the presence of a shoulder resonance at $\delta_{\text {iso }} \sim$ $9.0 \mathrm{ppm}$. The $2 \mathrm{D}{ }^{1} \mathrm{H}$ MAS DQ-SQ NMR spectrum of MIL-53(Al)$\mathrm{NH}_{2}$ /MMA (Fig. S13, ESI $\dagger$ ) demonstrates off-diagonal signals that indicate (i) a coupling of geminal $-\mathrm{CH}_{2}$ protons $\left(\delta_{\text {iso }}\right.$ in $\mathrm{F} 2$ dimension: 5.0-6.5 ppm) of the MMA functionality; (ii) a correlation between the bridging $\mu_{2}-\mathrm{OH}$ of the framework and trans- $\mathrm{CH}_{2}$ of the MMA group ( $\delta_{\text {iso }}$ in F2 dimension: 1.6-5.1 ppm) due to their spatial proximity; (iii) a correlation of the methyl-group of MMA ( $\delta_{\text {iso }}$ in F2 dimension: $0.7-8.0 \mathrm{ppm}$ ) and (iv) the bridging $\mu_{2}-\mathrm{OH}\left(\delta_{\text {iso }}\right.$ in $\mathrm{F} 2$ dimension: $\left.2.7-8.0 \mathrm{ppm}\right)$ with the aromatic 
protons. The appearance of resonances at $\sim 16.7,122.7$ and $166.0 \mathrm{ppm}$ in ${ }^{13} \mathrm{C}$ CP-MAS NMR spectrum (Fig. S14, ESI $\dagger$ ) can be associated with $-\mathrm{CH}_{3},-\mathrm{CH}_{2}$ and $\mathrm{C}=\mathrm{O}$ carbons of the MMA moiety anchored to $-\mathrm{NH}_{2}$ site of the MOF. Additionally, correlations at $\delta_{\text {iso }} \sim(16,0.6) \mathrm{ppm},(123,6.0) \mathrm{ppm}$ and $(160,9.9) \mathrm{ppm}$ corresponding to $-\mathrm{CH}_{3},-\mathrm{CH}_{2}$ and $\mathrm{C}(=\mathrm{O})-\mathrm{NH}$ fragments of the MMA functionality can be observed in the $2 \mathrm{D}{ }^{1} \mathrm{H}-{ }^{13} \mathrm{C}$ CP-MAS HETCOR NMR spectrum (Fig. S15, ESI $\dagger$ ).

To overcome sensitivity constraints of the ${ }^{15} \mathrm{~N}$ NMR measurements, DNP-enhanced ${ }^{15} \mathrm{~N}$ NMR experiments were carried out on MIL-53(Al)- $\mathrm{NH}_{2}$ and MIL-53(Al)- $\mathrm{NH}_{2}$ /MMA samples. As shown in Fig. $2 \mathrm{~B}$, the spectrum of the $\mathrm{PSM}-\mathrm{NH}_{2} / \mathrm{MMA}$ material reveals a resonance at $\sim 122 \mathrm{ppm}$ attributed to the newly formed $\mathrm{C}(=\mathrm{O})-\mathrm{NH}$ functionality in addition to the peak of the $-\mathrm{NH}_{2}$ group at $\sim 68 \mathrm{ppm}$, whereas only one strong signal at $\sim 72 \mathrm{ppm}$ of the $-\mathrm{NH}_{2}$ group is observed in the spectrum of the pristine MOF. Furthermore, a 2D DNP-enhanced ${ }^{15} \mathrm{~N}-{ }^{1} \mathrm{H}$ CP-MAS HETCOR NMR correlation map exposes two sets of cross-peaks attributed to the couplings between nitrogen atoms in $-\mathrm{NH}_{2}$ and $\mathrm{C}(=\mathrm{O})-\mathrm{NH}$ with the aromatic and amide protons (Fig. S20, ESI $\dagger$ ). All observations above indicate the covalent anchoring of MMA in the framework of MIL-53(Al)- $\mathrm{NH}_{2}$.

Additionally, the post-synthetic event in the MIL-53(Al)- $\mathrm{NH}_{2} /$ MMA structure was evidenced by thermogravimetric analysis (TGA) in an air atmosphere and argon physisorption measurements (Fig. S6C and D, ESI $\dagger$ ). Due to the incorporation of an additional MMA group, the mass loss in the region of $350-600{ }^{\circ} \mathrm{C}$, where a total organic component decomposition takes place, expanded by $12 \mathrm{wt} \%$ for the PSM material compared to that of the pristine compound (Table S5, ESI $\dagger$ ). Furthermore, the surface measurements reveal that the incorporation of the MMA group leads to a reduction in the intrinsic porosity from $370 \mathrm{~m}^{2} \mathrm{~g}^{-1}$ to $303 \mathrm{~m}^{2} \mathrm{~g}^{-1}$ (Fig. S6D and Table S5, ESI $\dagger$ ). In addition, a comparison of the FTIR spectra of the pristine and modified MIL-53(Al)- $\mathrm{NH}_{2}$ /MMA material reveals an increase in the relative intensity of the absorption band situated at $\sim 1610 \mathrm{~cm}^{-1}$, which is assigned to the $\mathrm{C}=\mathrm{C}$ vinylic group, further suggesting a conceivable PSM occurrence (Fig. S21, ESI $\dagger$ ).

In order to determine the percentage of amino groups acylated with MMA, the MIL-53(Al)- $\mathrm{NH}_{2}$ /MMA material was digested in a DMSO-d6 and HF mixture and evaluated by liquid-state ${ }^{1} \mathrm{H}$ NMR spectroscopy. The percentage of the modified $-\mathrm{NH}_{2}$ groups was estimated to be $34 \%$ by comparing the integrals of the characteristic geminal proton signals of the MMA group $(\delta=5.58,5.95 \mathrm{ppm})$ and the aromatic protons of the pristine $\mathrm{NH}_{2}-\mathrm{BDC}$ linker $(\delta=6.99-7.75 \mathrm{ppm})$ (Fig. S22, ESI $\left.\dagger\right)$. Considering the size of the MIL-53(Al)- $\mathrm{NH}_{2}$ nanoparticles (Fig. S7, ESI $\dagger$ ) and the orientation of the unit cell axes relative to the rodshaped nanocrystal facets (Fig. S23, ESI $\dagger$ ), ${ }^{46,47}$ the estimated amount of $-\mathrm{NH}_{2}$ groups located in the unit cells forming the crystal surface and exposed to PSM was approximated to be around $20 \%$. Thus, this value concedes the percentage of $-\mathrm{NH}_{2}$ acylated with MMA determined from the liquid NMR of the digested MIL-53(Al)- $\mathrm{NH}_{2}$ /MMA material, which suggests that the PSM process not only occurs on the surface of the nanoparticles, but also involves part of the porosity.
An essential criterion imposed on any photopolymerizable ink formulation is the velocity of photo-crosslinking events set in motion when exposed to a light source. Thus, the commencing step in the design of a MOF-containing ink formulation was to appraise the suitability of the precursor oligomer mixture for photopolymerization in terms of its behavior under illumination. The corresponding transformation was followed by time-resolved ATR-FTIR on several commercially available acrylate-based systems (Fig. S1 and Table S1, entries 1-6, ESI $\dagger$ ), which were intended to form a continuous matrix in printed composites, defining a decrease of $\sim 1640 \mathrm{~cm}^{-1}$ band area as a merit of methacrylic group conversion (Fig. S24, ESI $\dagger$ ). ${ }^{48}$ Fig. 3A summarizes the individual kinetic profiles of T, P, E and U-monomer photopolymerization and demonstrates a rapid MMA transformation in the P-system (with $2.4 \% \mathrm{~s}^{-1} v_{X_{\mathrm{MMA}}}^{50 \%}$ ) with an $X_{\mathrm{MMA}}$ conversion reaching $25 \%$ compared to more moderate photopolymerization velocities in the T- and E-components $\left(\sim 1.5 \% \mathrm{~s}^{-1}\right)$ that demonstrated an $X_{\mathrm{MMA}}$ conversion of $27 \%$ and $24 \%$, respectively (Fig. 3B). In contrast, the relatively slow behavior of the U-oligomer with a maximum degree of MMA conversion of $15 \%$ and a rate of $0.75 \% \mathrm{~s}^{-1}$ made it less desirable for further involvement in the DLP process. The viscosity of a photopolymerizable formulation is one of the governing factors that determines the kinetics of MMA crosslinking. As observed (Table S6, ESI $\dagger$ ), a higher viscosity of the precursor is correlated with slower kinetics of the photopolymerization process. This should not exceed values of about $600 \mathrm{cP}$ for the effective use with a moving build platform.

Subsequently, MOF-based blends with selected commercial oligomers ( $\mathrm{T}, \mathrm{P}, \mathrm{E}$ components) were admixed in a certain proportion (Table S1, entries 7, 8 and 10, ESI $\dagger$ ) and the kinetics of MMA conversion were elucidated. The polymerization rates of the heterogeneous formulations diminish by a factor of 3-4 compared to those of the systems without the MIL-53- $\mathrm{NH}_{2} / \mathrm{MMA}$ component (Fig. 3B), still reaching the same conversion levels observed for homogeneous mixtures (Fig. S25 and Table S7, ESI $\dagger$ ). Among the tested blends, T/MIL-53- $\mathrm{NH}_{2} / \mathrm{MMA}$ demonstrated the fastest response to the light (Fig. 3B), as evidenced by a pronounced drop for the ca. $1640 \mathrm{~cm}^{-1}$ band of the MMA group in a 2D ATR-FTIR spectra series (Fig. 3C), and can be used for the DLP printing process to yield solid films and 3D models of desired shapes (Fig. 3D and E).

As a covalent integration of the MIL-53- $\mathrm{NH}_{2} / \mathrm{MMA}$ nanoparticles into the matrix is an important aspect to consider, the ability of the functionalized MOF component to be grafted to the acrylic moieties of the matrix was elucidated with the help of confocal Raman spectroscopy. Fig. 4A depicts the Raman maps on the $30 \times 30 \mu \mathrm{m}^{2}$ area of the PSM-MOF-containing 3DP composite membrane in which the contrast scale corresponds to the intensity of the $\mathrm{C}-(\mathrm{C}=\mathrm{O})-\mathrm{O}$ symmetrical stretching band $\left(\sim 600 \mathrm{~cm}^{-1}\right)$ attributed to the MMA moieties involved in copolymerization (Fig. S26D, ESI $\dagger$ ). The contrast scale ranges from the strongest (wine) to the weakest (navy) scattering intensities; the sketching zones with a lower crosslinking density of MMA in the dark blue and cyan regions visualize regions where the 

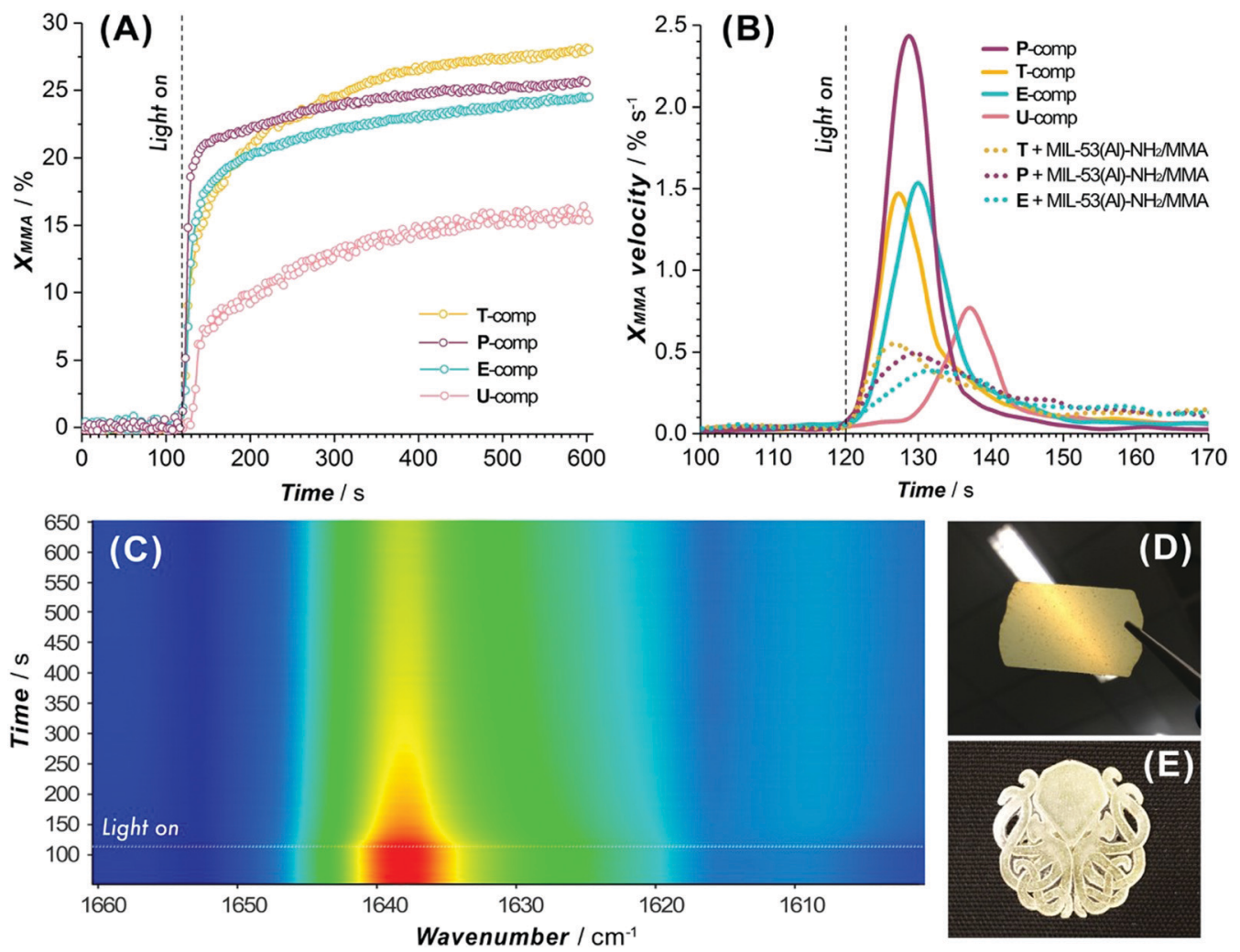

Fig. 3 (A) Kinetic profiles of photopolymerization for individual oligomer mixtures (T, P, E and U-components). (B) Comparison of MMA-group conversion velocities for individual oligomers and MOF-contained formulations under the printer light source (turn on at 120 s). (C) 2D-resolved ATR-FTIR spectrum of a T/MIL-53(Al)- $\mathrm{NH}_{2} /$ MMA photopolymerization event (lamp on at $120 \mathrm{~s}$ ). Image of a $50 \mu \mathrm{m}$ thick printed film viewed against the light (D) and a three-layer printed model (E) both based on T/MIL-53(Al)- $\mathrm{NH}_{2} / \mathrm{MMA}$ ink.

concentration of crosslinked MMA moieties is higher. Taking into account the previous findings that the MMA conversion in MIL-53- $\mathrm{NH}_{2} / \mathrm{MMA}$-acrylate systems usually does not exceed $27-30 \%$ in total and considering that the MIL-53- $\mathrm{NH}_{2} / \mathrm{MMA}$ component and matrix oligomer mixtures both have the crosslinked functionality, relatively homogenous cross-linking in the 3D printed composite despite PSM-MOF additive inclusion can be achieved. Furthermore, the intensity ratios of specific Raman bands related to the acrylic part (both matrix and $\mathrm{PSM}-\mathrm{NH}_{2}$ / MMA MOF) and the aromatic component of the linker (PSM$\mathrm{NH}_{2}$ /MMA MOF) were compared on 2D contrast maps to provide information on the local chemical composition and distribution of the MOF additive in the accessible depth of the 3DP material. The distribution of MIL-53- $\mathrm{NH}_{2}$ /MMA nanoparticles within the acrylic matrix was evaluated from the intensity ratios of the Raman band centered at $\sim 1450 \mathrm{~cm}^{-1}$ (the aromatic ring $\mathrm{C}-\mathrm{C}$ chain vibration in the MIL-53(Al) framework) relative to the $\mathrm{C}=\mathrm{O}$ symmetric stretching vibration in the MMA group located at $\sim 1730 \mathrm{~cm}^{-1}$ (Fig. S26A-C, ESI $\dagger$ ). As shown in Fig. 4B, the distinguished regions of the PSM- $\mathrm{NH}_{2} / \mathrm{MMA}$ MOF component can be mapped where the pixels of colours from cyan to yellow are located, occupying areas of one order of magnitude bigger than the average nanoparticle size of the MIL-53- $\mathrm{NH}_{2} / \mathrm{MMA}$ additive. The FIB-SEM cross-sectional studies of the 3DP composite membrane further disclose the MIL-53- $\mathrm{NH}_{2} / \mathrm{MMA}$ clustering and unveil a structural feature of the observed lumps (Fig. 4C). Although the MOF distribution within the polymerized matrix is not perfectly uniform (Fig. 4E and F), individual MIL-53- $\mathrm{NH}_{2} /$ MMA nanoparticles are surrounded by the polymer, suggesting a proper integration of the filler without the formation of voids. Notably, the structure of the polyacrylate matrix itself does not possess visible intrinsic porosity compared to that of the conventional polymeric matrices used in the preparation of MMMs (Fig. 4D). The gas adsorption measurements using $\mathrm{CO}_{2}$ as a probe molecule further corroborate this observation (Fig. S27, ESI $\dagger$ ). Despite the chemical differences in the acrylate systems employed as a matrix precursor, the shapes of the adsorption isotherms reveal large sorption-desorption hysteresis loops along a wide range of pressures as a common attribute of glassy polymers ${ }^{49}$ albeit severe divergence in the total adsorption capacity from $0.01 \mathrm{mmol} \mathrm{g}^{-1}$ for the T- to $0.14 \mathrm{mmol} \mathrm{g}^{-1}$ for the U-component and $\sim 0.17 \mathrm{mmol} \mathrm{g}^{-1}$ for the $2 / 3 \mathrm{~T}+1 / 3 \mathrm{U}$ mixture (Fig. S27A, ESI $\dagger$ ).

The hysteresis loop feature is a characteristic aspect of many polymethylmethacrylate systems and is caused by the ability of these systems to undergo $\mathrm{CO}_{2}$-induced swelling associated with a glassy-to-rubbery state transition. ${ }^{50-52}$ As expected, the adsorption capacity of a printed composite increases with an inclusion of a MIL-53- $\mathrm{NH}_{2} / \mathrm{MMA}$ component (Fig. S27B, ESI $\dagger$ ), which contributes to the boost of the total gas uptake at its microporous surface. 

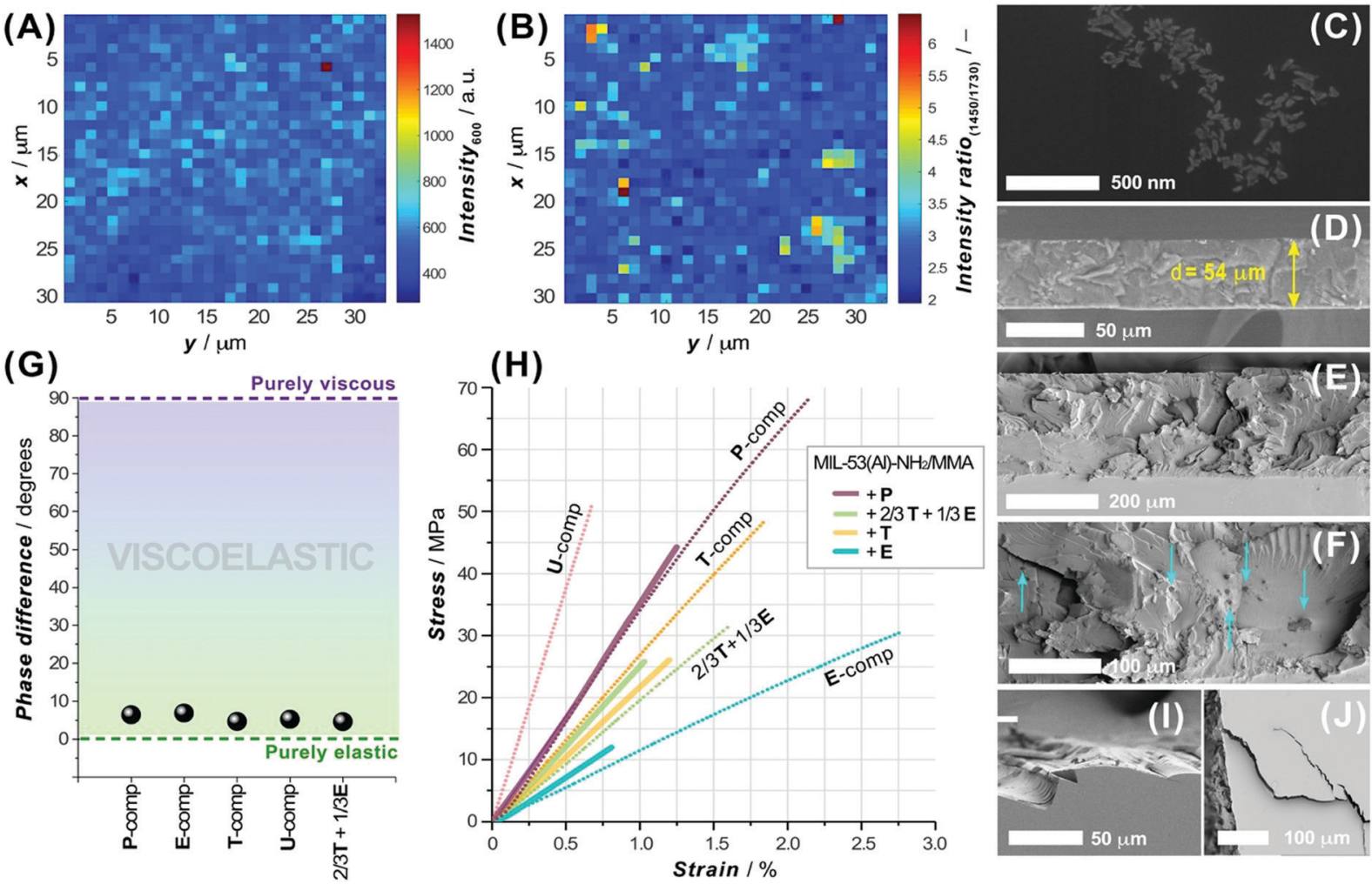

Fig. 4 (A and B) Raman maps of a 3D printed membrane $\left(30 \times 30 \mu \mathrm{m}^{2}\right.$ area, step size of $\left.1 \mu \mathrm{m}\right)$ depicting the spatial distribution of (A) the intensity of the characteristic band from MMA functionality and (B) the band intensity ratios of the distinguished frequencies in MIL-53(Al) relative to the MMA component. (C) FIB-SEM cross-section and (D) SEM image of an $\mathrm{N}_{2}$ cracked $54 \mu \mathrm{m}$ thick T/MIL-53-NH $2 / M M A$ 3DP membrane (3DP-M). (E and F) Crosssectional (liquid $\mathrm{N}_{2}$ ) views of 3DP-M at different magnifications revealing MIL-53- $\mathrm{NH}_{2} / M M A$ lumps (indicated with arrows). (G) Phase difference ( $\delta$ ) between the stress and strain values of pure $P, E, T, U-3 D P$ systems and $2 / 3 T+1 / 3 E$ mixture on a viscoelastic reference diagram. (H) Stress and strain curves of pure $\mathrm{P}, \mathrm{E}, \mathrm{T}, \mathrm{U}$ and $2 / 3 \mathrm{~T}+1 / 3 \mathrm{E}$ 3DP materials (dotted lines) and their MOF-based composites (solid lines). Brittle fracture (I) and cracks (J) produced by the fracturing of a T/MIL-53-NH $/$ MMA 3DP-M.

In order to be used in gas separation processes, either purely polymeric or composite membranes require sufficient mechanical stability and flexible resistivity at the conditions close to real operation settings. ${ }^{53}$ To assess the mechanical properties of the DLP 3D printed materials studied here, specimens of various photopolymerizable systems and blends were tested by applying dynamic mechanical and uniaxial tensile analyses. The dynamic tensile data for a commercially available acrylate ink (P, E, T and U), used as a matrix component in our formulations, and a mixture $(2 / 3 \mathrm{~T}+1 / 3 \mathrm{E})$ were compared using a viscoelastic reference diagram (Fig. 4G). Evidently, the elastic nature of these photopolymerizable matrix systems significantly prevails over their viscous counterparts and the phase difference $(\delta)$ in the stress-strain responses deviates slightly from one component to another. As anticipated, the MIL-53$\mathrm{NH}_{2}$ /MMA-based composites exhibit a lower damping factor $(\tan \delta$ ) compared to that of a pure polymeric material, agreeing well with the commonly observed trends (Table S8, ESI $\dagger$ ). ${ }^{54}$ Furthermore, the shape of the stress-strain curves for the 3DP polymeric and MOF-based materials suggests the brittle nature of the acrylate crosslinked systems, whose chemical composition defines the mechanical properties expressed in terms of Young's modulus $(E)$, and stress $\left(\sigma_{\mathrm{R}}\right)$ and strain at break $\left(\varepsilon_{\mathrm{R}}\right)$ values (Table S8, ESI $\dagger$ ). Hence, the 3DP U-component shows the highest tensile strength $\left(\sigma_{\mathrm{R}}=50.6 \mathrm{MPa}, \varepsilon_{\mathrm{R}}=0.67 \%\right)$ among the other matrix inks, while the E-system, in turn, reveals superior toughness $\left(\sigma_{\mathrm{R}}=30.2 \mathrm{MPa}, \varepsilon_{\mathrm{R}}=2.75 \%\right)$. Certainly, the brittle behaviour of the 3DP composite can also be noted in the corresponding cross-sectional views (Fig. 4E, I and J), where typical brittle fracture patterns and cracks can be observed. It is worth noting that the MOF filler commonly contributes to an earlier rupture of the 3DP composite, presumably due to the formation of discretely localized heterogeneous inclusions and defects that can contribute to the origin and propagation of cracks. Overall, the MIL-53- $\mathrm{NH}_{2} / \mathrm{MMA}$-based acrylate 3DP materials display high tensile strengths and are able to withstand the conditions applied in gas separation processes.

Membranes based on a polymer in the glassy state are known to be particularly attractive for the selective separation of $\mathrm{H}_{2}$ from $\mathrm{H}_{2} / \mathrm{CO}_{2}$ mixtures. ${ }^{55}$ Considering the above information, the 3DP acrylate-based membranes were assumed to be applicable in $\mathrm{H}_{2} / \mathrm{CO}_{2}$ separation and therefore subjected to mixed gas separation tests to unveil their potential. The selection of the 3DP membrane formulation was rationalized considering the optimal DLP processing parameters, mechanical properties discussed above and glass transition temperatures $\left(T_{\mathrm{g}}\right)$ of pure 
continuous phases and MIL-53- $\mathrm{NH}_{2}$ /MMA-based composites (Table S11, ESI $\dagger$ ). The U-based formulations were excluded due to their poor DLP processing performance, whereas P-systems show a comparatively low $T_{\mathrm{g}}$ value (Table S11, ESI $\dagger$ ) limiting the available temperature range of $\mathrm{H}_{2} / \mathrm{CO}_{2}$ gas separation. Thus, the T-component system was selected for further separation of an equimolar mixture of $\mathrm{H}_{2}$ and $\mathrm{CO}_{2}$ at two different temperatures ( $323 \mathrm{~K}$ and $373 \mathrm{~K}$ ) and 2 bar absolute feed pressure. All the prepared membranes can withstand the permeation test conditions. Fig. 5A summarizes the separation data for the pure T-matrix and T + MIL53- $\mathrm{NH}_{2} / \mathrm{MMA}$ composite 3DP membranes.

The incorporation of MIL-53- $\mathrm{NH}_{2} /$ MMA nanoparticles (12 wt\% loading) crosslinked with a continuous matrix leads to a significant increase in $\mathrm{H}_{2}$ and $\mathrm{CO}_{2}$ permeabilities preserving the original T-component membrane selectivity at $323 \mathrm{~K}$. These observations agree with the fact that the porous filler can provide additional
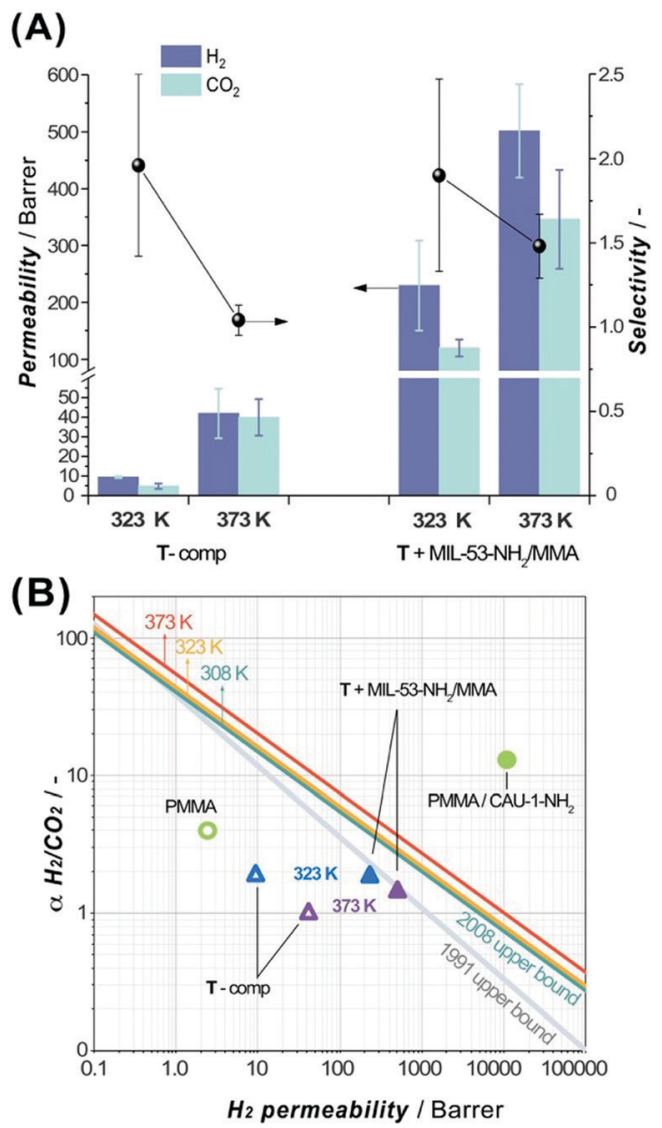

Fig. 5 (A) $\mathrm{H}_{2}$ (violet columns, mint error bars) and $\mathrm{CO}_{2}$ (mint columns, violet error bars) permeabilities and $\mathrm{H}_{2} / \mathrm{CO}_{2}$ selectivity (black spheres, black error bars) for a 3DP membrane containing pure T-comp or T + MIL53- $\mathrm{NH}_{2} /$ MMA (12 wt\% of MOF component) formulation in an equimolar $\mathrm{H}_{2} / \mathrm{CO}_{2}$ gas mixture at different temperatures ( $323 \mathrm{~K}$ and $373 \mathrm{~K}$ ) and measured at 2 bar absolute feed pressure. (B) Comparison of separation performance for $\mathrm{T}$-comp (empty triangle) or $\mathrm{T}+\mathrm{MIL}-53-\mathrm{NH}_{2} / \mathrm{MMA}$ (solid triangle) 3DP membrane (at $323 \mathrm{~K}$ and $373 \mathrm{~K}$, blue and violet, respectively) with previously reported pure PMMA ( 2 bar, $303 K$, green empty circle) $)^{57}$ and PMMA/CAU-1- $\mathrm{NH}_{2}$ (green solid circle, 3 bar, $298 \mathrm{~K}, 15 \mathrm{wt} \%$ of MOF) composites. ${ }^{56}$ The lines represent the 1991 Robeson upper bounds (grey line) and updated to 2008, plotted for $308 \mathrm{~K}$ (green), $323 \mathrm{~K}$ (yellow) and $373 \mathrm{~K}(\mathrm{red}){ }^{58,59}$ pathways for the permeating gases. However, the low $\mathrm{H}_{2} / \mathrm{CO}_{2}$ selectivity in the studied membranes compared to that of the other reported relevant $\mathrm{MMMs}^{56,57}$ (Fig. 5B) suggests the presence of non-selective paths for penetrant gas molecules around the filler particles. Upon increasing the temperature up to $373 \mathrm{~K}$, the permeabilities of the bare T-polymer and $\mathrm{T}+\mathrm{MIL}-53-\mathrm{NH}_{2} /$ MMA composites both increase about one order of magnitude $\left(P_{\mathrm{H}_{2}}=41.9 \pm 12.6, P_{\mathrm{CO}_{2}}=39.9 \pm 9.3\right.$ versus $P_{\mathrm{H}_{2}}=9.4 \pm 0.4, P_{\mathrm{CO}_{2}}=$ $4.8 \pm 1.4$ Barrer and $P_{\mathrm{H}_{2}}=501.4 \pm 81.9, P_{\mathrm{CO}_{2}}=345.9 \pm 87.1$ versus $P_{\mathrm{H}_{2}}=229.3 \pm 79.3, P_{\mathrm{CO}_{2}}=119.6 \pm 14.4$ Barrer, respectively, Table S12, ESI $\dagger$ ), and meanwhile, the $\mathrm{H}_{2} / \mathrm{CO}_{2}$ selectivity drops, reflecting a loss of the size-sieving ability, most significantly in the case of pure T-acrylate matrix. The permeability enhancement can be attributed to an increase in the diffusivity of the gases through the polymeric matrix at higher temperatures. It should be noted that the milder drop of the selectivity in the MIL-53- $\mathrm{NH}_{2} / \mathrm{MMA}$ grafted T-composite membrane at $373 \mathrm{~K}$ indicates a beneficial collaborative interaction between the continuous and dispersed phases, resulting in a selective contribution of the filler to the total $\mathrm{H}_{2} / \mathrm{CO}_{2}$ sieving performance. The permeation results of the pure T-matrix and $\mathrm{T}+\mathrm{MIL}-53-\mathrm{NH}_{2} / \mathrm{MMA}$ composite membranes at $323 \mathrm{~K}$ and $373 \mathrm{~K}$ are plotted against the 2008 Robeson upper bounds ${ }^{59}$ for selected temperatures (Fig. 5B). ${ }^{58}$ Specifically, the separation performance of the 3DP membranes explored in this study lies below the empirical selectivity-permeability trend line for the $\mathrm{H}_{2} / \mathrm{CO}_{2}$ gas pair and occupies a modest position in the graph. Compared to the best performing and chemically related polymethyl methacrylate (PMMA)-based MMM-containing CAU1- $\mathrm{NH}_{2}$ filler (Fig. 5B), the 3DP $\mathrm{T}+\mathrm{MIL}-53-\mathrm{NH}_{2} / \mathrm{MMA}$ membrane demonstrates significantly lower permeability and selectivity. This can be explained in light of chemical, textural and structural differences between these two systems. As 3DP DLP processing requires highly crosslinked methacrylic matrices to enable control over the resulting solid shape, the low permeability is an expected and inevitable outcome, whereas MMMs prepared by a conventional casting method can possess large free volumes that result in high permeabilities. ${ }^{56}$ Moreover, the preliminary obtained gas separation results for the $\mathrm{T}+\mathrm{MIL}-53-\mathrm{NH}_{2}$ formulation comprising pristine MOF revealed a non-selective behaviour caused by the poor interaction between the filler and polymer which leads to the formation of defects, and these results were approved using the MOF grafted with methacrylic functionality. Overall, the obtained results suggest that the 3D DLP technology can be used in fast prototyping of MOF-based MMMs, leaving room for further development of ink formulations by varying the content of the polymeric matrix along with the type of the MOF component.

\section{Conclusion}

In this work, we have demonstrated a fast and convenient approach to manufacture MOF-based polymer composite membranes using a conventional DLP 3D printer. MOF-based photopolymerizable inks formulated from post-synthetically functionalized MIL-53(Al)- $\mathrm{NH}_{2}$ /MMA nanoparticles and acrylate oligomers are 
fully compatible with conventional 3D printing. It was evidenced that the MOF-based photopolymerizable systems undergo a photoinduced crosslinking with the matrix components at a relatively fast rate reaching the degree of crosslinking comparable with the pure oligomer mixtures. Hence, fulfilling the criteria for the DLP process, the MIL-53(Al)- $\mathrm{NH}_{2} / \mathrm{MMA}$-containing inks can be transformed into free-standing composite membranes with desirable thickness and shape. The mechanical properties of the resulting 3D printed composites, glassy state of the polymeric media and microporosity provided by the MOF component enable their use as mixed matrix membranes for gas separation applications. The sieving behavior of the 3D printed MOF-MMMs in an equimolar $\mathrm{H}_{2} / \mathrm{CO}_{2}$ gas mixture indicates the enhanced permeability of the MIL-53(Al)- $\mathrm{NH}_{2} / \mathrm{MMA}$-containing composite in comparison to that observed for the bare polymer.

Finally, it was shown that the $3 \mathrm{D}$ printing technology involving digital light processing could be successfully applied for fast prototyping of MOF-based mixed membranes and sets a basis for further development in this field.

\section{Conflicts of interest}

There are no conflicts to declare.

\section{Acknowledgements}

A. P., E. A.-H. and J. G. acknowledge King Abdullah University of Science and Technology (KAUST) for the financial support. B. S. was supported by her personal VENI grant (The Netherlands National Science Foundation, NWO). The authors gratefully acknowledge Sartomer (Arkema Group) for providing them with the samples of acrylate oligomer mixtures used in this study.

\section{References}

1 S. C. Ligon, R. Liska, J. Stampfl, M. Gurr and R. Mülhaupt, Chem. Rev., 2017, 117, 10212.

2 M. R. Hartings and Z. Ahmed, Nat. Rev. Chem., 2019, 3, 305.

3 L. D. Tijing, J. R. C. Dizon, I. Ibrahim, A. R. N. Nisay, H. K. Shon and R. C. Advincula, Appl. Mater. Today, 2020, 18, 100486.

4 C. Parra-Cabrera, C. Achille, S. Kuhn and R. Ameloot, Chem. Soc. Rev., 2018, 47, 209.

5 R. L. Truby and J. A. Lewis, Nature, 2016, 540, 371.

6 T. D. Ngo, A. Kashani, G. Imbalzano, K. T. Q. Nguyen and D. Hui, Composites, Part B, 2018, 143, 172.

7 X. Zhou and C.-j. Liu, Adv. Funct. Mater., 2017, 27, 1701134.

8 X. Yun, B. Lu, Z. Xiong, B. Jia, B. Tang, H. Mao, T. Zhang and X. Wang, RSC Adv., 2019, 9, 29384.

9 E. Davoodi, H. Montazerian, R. Haghniaz, A. Rashidi, S. Ahadian, A. Sheikhi, J. Chen, A. Khademhosseini, A. S. Milani, M. Hoorfar and E. Toyserkani, ACS Nano, 2020, 14, 1520.

10 H. Furukawa, K. E. Cordova, M. O’Keeffe and O. M. Yaghi, Science, 2013, 341, 1230444.

11 A. Bavykina, N. Kolobov, I. S. Khan, J. A. Bau, A. Ramirez and J. Gascon, Chem. Rev., 2020, 120, 8468.
12 A. Pustovarenko, A. Dikhtiarenko, A. Bavykina, L. E. M. Gevers, A. Ramirez, A. Russkikh, S. Telalovic, A. A. Tapia, J. L. Hazemann, S. Ould-Chikh and J. Gascon, ACS Catal., 2020, 10, 5064.

13 B. Seoane, J. Coronas, I. Gascon, M. E. Benavides, O. Karvan, J. Caro, F. Kapteijn and J. Gascon, Chem. Soc. Rev., 2015, 44, 2421.

14 J. Yang and Y.-W. Yang, Small, 2020, 16, 1906846.

15 W.-T. Koo, J.-S. Jang and I.-D. Kim, Chem, 2019, 5, 1938.

16 L. L. da Luz, R. Milani, J. F. Felix, I. R. B. Ribeiro, M. Talhavini, B. A. D. Neto, J. Chojnacki, M. O. Rodrigues and S. A. Júnior, ACS Appl. Mater. Interfaces, 2015, 7, 27115.

17 J. L. Zhuang, D. Ar, X. J. Yu, J. X. Liu and A. Terfort, Adv. Mater., 2013, 25, 4631.

18 H. Thakkar, S. Eastman, Q. Al-Naddaf, A. A. Rownaghi and F. Rezaei, ACS Appl. Mater. Interfaces, 2017, 9, 35908.

19 P. Pei, Z. Tian and Y. Zhu, Microporous Mesoporous Mater., 2018, 272, 24.

20 H. Thakkar, Q. Al-Naddaf, N. Legion, M. Hovis, A. Krishnamurthy, A. A. Rownaghi and F. Rezaei, ACS Sustainable Chem. Eng., 2018, 6, 15228.

21 J. Lefevere, B. Claessens, S. Mullens, G. Baron, J. Cousin-SaintRemi and J. F. M. Denayer, ACS Appl. Nano Mater., 2019, 2, 4991.

22 G. J. H. Lim, Y. Wu, B. B. Shah, J. J. Koh, C. K. Liu, D. Zhao, A. K. Cheetham, J. Wang and J. Ding, ACS Mater. Lett., 2019, 1, 147.

23 Z. Lyu, G. J. H. Lim, R. Guo, Z. Kou, T. Wang, C. Guan, J. Ding, W. Chen and J. Wang, Adv. Funct. Mater., 2019, 29, 1806658.

24 S. Lawson, Q. Al-Naddaf, A. Krishnamurthy, M. S. Amour, C. Griffin, A. A. Rownaghi, J. C. Knox and F. Rezaei, ACS Appl. Mater. Interfaces, 2018, 10, 19076.

25 S. Sultan, H. N. Abdelhamid, X. D. Zou and A. P. Mathew, Adv. Funct. Mater., 2019, 29, 1805372.

26 A. J. Young, R. Guillet-Nicolas, E. S. Marshall, F. Kleitz, A. J. Goodhand, L. B. L. Glanville, M. R. Reithofer and J. M. Chin, Chem. Commun., 2019, 55, 2190.

27 J. Dhainaut, M. Bonneau, R. Ueoka, K. Kanamori and S. Furukawa, ACS Appl. Mater. Interfaces, 2020, 12, 10983.

28 M. Bible, M. Sefa, J. A. Fedchak, J. Scherschligt, B. Natarajan, Z. Ahmed and M. R. Hartings, 3D Print. Addit. Manuf., 2018, 5, 63.

29 M. N. Channell, M. Sefa, J. A. Fedchak, J. Scherschligt, M. Bible, B. Natarajan, N. N. Klimov, A. E. Miller, Z. Ahmed and M. R. Hartings, Polym. Adv. Technol., 2018, 29, 867.

30 K. A. Evans, Z. C. Kennedy, B. W. Arey, J. F. Christ, H. T. Schaef, S. K. Nune and R. L. Erikson, ACS Appl. Mater. Interfaces, 2018, 10, 15112.

31 O. Halevi, J. M. R. Tan, P. S. Lee and S. Magdassi, Adv. Sustainable Syst., 2018, 2, 1700150.

32 E. Lahtinen, R. L. M. Precker, M. Lahtinen, E. Hey-Hawkins and M. Haukka, ChemPlusChem, 2019, 84, 222.

33 R. Li, S. Yuan, W. Zhang, H. Zheng, W. Zhu, B. Li, M. Zhou, A. Wing-Keung Law and K. Zhou, ACS Appl. Mater. Interfaces, 2019, 11, 40564.

34 A. Figuerola, D. A. V. Medina, A. J. Santos-Neto, C. P. Cabello, V. Cerdà, G. T. Palomino and F. Maya, Appl. Mater. Today, 2019, 16, 21. 
35 J. Dechnik, J. Gascon, C. J. Doonan, C. Janiak and C. J. Sumby, Angew. Chem., Int. Ed., 2017, 56, 9292.

36 Y. Zhang, X. Feng, H. Li, Y. Chen, J. Zhao, S. Wang, L. Wang and B. Wang, Angew. Chem., Int. Ed., 2015, 54, 4259.

37 A. Sabetghadam, B. Seoane, D. Keskin, N. Duim, T. Rodenas, S. Shahid, S. Sorribas, C. Le Guillouzer, G. Clet, C. Tellez, M. Daturi, J. Coronas, F. Kapteijn and J. Gascon, Adv. Funct. Mater., 2016, 26, 3154.

38 M. Kandiah, S. Usseglio, S. Svelle, U. Olsbye, K. P. Lillerud and M. Tilset, J. Mater. Chem., 2010, 20, 9848.

39 American Society for Testing and Materials and ASTM, ASTM D2765-11, 2006.

40 P. Serra-Crespo, E. Gobechiya, E. V. Ramos-Fernandez, J. Juan-Alcañiz, A. Martinez-Joaristi, E. Stavitski, C. E. A. Kirschhock, J. A. Martens, F. Kapteijn and J. Gascon, Langmuir, 2012, 28, 12916.

41 A. Pustovarenko, M. G. Goesten, S. Sachdeva, M. Shan, Z. Amghouz, Y. Belmabkhout, A. Dikhtiarenko, T. Rodenas, D. Keskin, I. K. Voets, B. M. Weckhuysen, M. Eddaoudi, L. C. P. M. de Smet, E. J. R. Sudhölter, F. Kapteijn, B. Seoane and J. Gascon, Adv. Mater., 2018, 30, 1707234.

42 S. Castellanos, K. B. Sai Sankar Gupta, A. Pustovarenko, A. Dikhtiarenko, M. Nasalevich, P. Atienzar, H. García, J. Gascon and F. Kapteijn, Eur. J. Inorg. Chem., 2015, 4648.

43 S. Couck, E. Gobechiya, C. E. A. Kirschhock, P. Serra-Crespo, J. Juan-Alcañiz, A. Martinez Joaristi, E. Stavitski, J. Gascon, F. Kapteijn, G. V. Baron and J. F. M. Denayer, ChemSusChem, 2012, 5, 740.

44 S. Devautour-Vinot, G. Maurin, C. Serre, P. Horcajada, D. Paula da Cunha, V. Guillerm, E. de Souza Costa, F. Taulelle and C. Martineau, Chem. Mater., 2012, 24, 2168.
45 M. Haouas, C. Volkringer, T. Loiseau, G. Férey and F. Taulelle, Chem. - Eur. J., 2009, 15, 3139.

46 J. M. Chin, E. Y. Chen, A. G. Menon, H. Y. Tan, A. T. S. Hor, M. K. Schreyer and J. Xu, CrystEngComm, 2013, 15, 654.

47 B. Seoane, S. Castellanos, A. Dikhtiarenko, F. Kapteijn and J. Gascon, Coord. Chem. Rev., 2016, 307, 147.

48 E. Gulari, K. McKeigue and K. Y. S. Ng, Macromolecules, 1984 17, 1822.

49 R. M. Conforti and T. A. Barbari, Macromolecules, 1993, 26, 5209.

50 X.-K. Li, G.-P. Cao, L.-H. Chen, R.-H. Zhang, H.-L. Liu and Y.-H. Shi, Langmuir, 2013, 29, 14089.

51 D. Liu, H. Li, M. S. Noon and D. L. Tomasko, Macromolecules, 2005, 38, 4416.

52 A. Rajendran, B. Bonavoglia, N. Forrer, G. Storti, M. Mazzotti and M. Morbidelli, Ind. Eng. Chem. Res., 2005, 44, 2549.

53 K. Wang, A. A. Abdala, N. Hilal and M. K. Khraisheh, in Membrane Characterization, ed. N. Hilal, A. F. Ismail, T. Matsuura and D. Oatley-Radcliffe, Elsevier, 2017, p. 259, DOI: 10.1016/b978-0-444-63776-5.00013-9.

54 V. Panwar and K. Pal, in Clay-Polymer Nanocomposites, ed. K. Jlassi, M. M. Chehimi and S. Thomas, Elsevier, 2017, p. 413, DOI: 10.1016/b978-0-323-46153-5.00012-4.

55 L. Shao, B. T. Low, T.-S. Chung and A. R. Greenberg, J. Membr. Sci., 2009, 327, 18.

56 L. Cao, K. Tao, A. Huang, C. Kong and L. Chen, Chem. Commun., 2013, 49, 8513.

57 C. J. Orme, M. L. Stone, M. T. Benson and E. S. Peterson, Sep. Sci. Technol., 2003, 38, 3225.

58 B. W. Rowe, L. M. Robeson, B. D. Freeman and D. R. Paul, J. Membr. Sci., 2010, 360, 58.

59 L. M. Robeson, J. Membr. Sci., 2008, 320, 390. 